\title{
(IN)DETERMINAÇÃO E SUBJETIVIDADE NA LINGUAGEM DE AFÁSICOS: A INCLINAÇÃO ANTI-REFERENCIALISTA DOS PROCESSOS ENUNCIATIVOS
}

\author{
EDWIGES MARIA MORATO ${ }^{12}$ \\ UNICAMP
}

\begin{abstract}
This paper presents some issues raised by a enunciative approach of referencing and subjectivity in the aphasic context. For this purpose, we extract our analysis from the empirical material of our investigation about signification process in a conversational situation within the pathological context. First, some assumptions of this approach are discussed, focussing on the interlocutives activities of the aphasics and non-aphasic subjects. Then some consequences for the neurolinguistic study are explicitated.
\end{abstract}

\section{INTRODUÇÃO}

A questão da subjetividade no campo da Lingüística - que acompanha de certo modo as crises da Filosofia ou da Psicologia sobre o tema - tem mudado de estatuto ao longo das últimas décadas, sem que tenha sido criada qualquer teoria verdadeiramente inovadora a seu respeito e sem que tenha perdido sua consistência enquanto fonte de conhecimento sobre a linguagem e seu funcionamento (ou mesmo enquanto um saber científico que temos sobre ele). Por outro lado, estudos recentes sobre a referenciação no campo da Análise da Conversação, da Lingüística Textual e da Enunciação recolocam em cena aspectos pragmáticos e antropológicos ligados de alguma maneira à subjetividade, analisada em meio às inúmeras atividades psico-sociais das práticas humanas. Neste artigo, procuro mostrar que a referenciação, enquanto tema de análise, traz à tona tanto a questão da subjetividade quanto a dos procedimentos 'meta' (metalingüísticos, meta-enunciativos, metadiscursivos) em jogo na linguagem de sujeitos afásicos ( rrosso modo, aqueles que em função de uma lesão cerebral adquirida passam a conviver com diferentes alterações lingüístico-cognitivas).

\footnotetext{
${ }^{1}$ Pesquisadora do CNPq (Proc. 301396/96-5) e da FAPESP (Proc. 01/05340-7).

${ }^{2}$ Gostaria de agradecer a Leonor Scliar e Lorenza Mondada pelos comentários sobre certas passagens deste artigo; sem dúvida, isso me fez pensar melhor e ser mais clara, o que naturalmente não quer dizer que me fez pensar com toda correção. Assim, as impropriedades aqui existentes são naturalmente de minha inteira responsabilidade.
} 
A análise da reconstrução do tecido enunciativo no contexto das afasias poderia nos dizer muito sobre formas de manutenção da inteligibilidade do mundo e das relações pragmático-sociais no âmbito das patologias cerebrais e no âmbito da "normalidade". No limite, são as relações entre linguagem e cognição, bem como entre língua e exterioridade - zonas do conhecimento (isto é, de interpretação), tomadas em geral como dicotômicas e como logicamente heterogêneas entre si - que se tornam passíveis de reconsideração. Na verdade, o caráter inovador desse empreendimento pode estar no fato de que o objeto de análise passa a ser a particularidade e o modo de funcionamento dessas relações que se dão no contexto patológico, e não o seu caráter mais ou menos patológico.

É, pois, no "campo anônimo das práticas" (para usar a expressão que Foucault emprega para se referir à origem do discurso em "A Arqueologia do Saber"), que a subjetividade (nem imputada a um sujeito transcendental, nem reduzida a uma subjetividade psicológica; nem ausente de ilusão de subjetividade, nem à margem da impositividade narcísica e individualista do "eu" nas sociedades modernas) permanece como tema importante para quem se interessa pelas questões de linguagem e de cognição no campo da Lingüística.

Antes mesmo de passar à discussão específica deste artigo, eu gostaria de proceder a um necessário prolongamento do presente preâmbulo. Apenas para que se admita que a inspiração decisiva deste artigo partiu da consideração de algumas passagens célebres de dois autores - Mikhail Bakhtin e Carlos Franchi - que, separados em perspectiva e tempo, orientaram, cada um à sua maneira, seus estudos sobre a linguagem a partir de uma mesma tese, que poderíamos chamar anti-referencialista, na qual se pode identificar, entre outros movimentos epistemológicos, a crucialidade do sujeito constituído na e pela linguagem - uma postulação tipicamente enunciativa que rejeita o princípio regulador da significação e a estabilidade do referente fora dos processos interativos.

A fim de ilustrar como subjetividade e anti-referencialismo são elevados por esses dois autores à condição de princípio, transcrevo aqui parte das reflexões de ambos sobre a questão. Primeiramente, vejamos o que nos diz Franchi: "A língua dispõe de múltiplos recursos expressivos que, associados a fatores como o contexto, a situação, a relação entre interlocutores, as leis conversacionais, etc. fornecerão condições de determinação de um dado enunciado. Por outro lado, o fato de que os sistemas de referência são culturais e dependentes da experiência, fazem postular a indeterminação semântica; de fato, 'as expressões das línguas naturais não tomam nunca um domínio de interpretação uno e semanticamente coerente na medida em que a linguagem não é somente uma linguagem do mundo 'real' e atual, mas permite uma constante revisão das categorias para falar-se de outros universos compossíveis'” (1977).

Em seguida, tomemos o seguinte trecho de Bakhtin: "Ora, se aquilo que se divide e subdivide em unidades de língua é indeterminado e vago, a indeterminação e a confusão se transmitem igualmente às unidades assim obtidas (...) A indeterminação $e$ a confusão terminológicas acerca de um ponto metodológico tão central no pensamento lingüístico resultam de um menosprezo total pelo que é a unidade real da 
comunicação verbal: o enunciado. A fala só existe, na realidade, na forma concreta dos enunciados de um indivíduo: do sujeito de um discurso-fala. O discurso se molda sempre à forma do enunciado que pertence a um sujeito e não pode existir fora dessa forma" (1952/1997). Tomemos de Bakhtin ainda mais um outro trecho: "A língua materna - a composição de seu léxico e sua estrutura gramatical - não a aprendemos nos dicionários e nas gramáticas, nós a adquirimos mediante enunciados concretos que ouvimos e reproduzimos durante a comunicação verbal viva que se efetua com os indivíduos que nos rodeiam. Assimilamos as formas da língua somente nas formas assumidas pelo enunciado e juntamente com essas formas (...) Aprender a falar é aprender a estruturar enunciados (porque falamos por enunciados e não por orações isoladas e, menos ainda, é óbvio, por palavras isoladas)" (1929/1995).

Tendo em vista as reflexões acima, este artigo parte, dentro dos limites de seu interesse, dos seguintes princípios: i) as línguas naturais são indeterminadas; ii) se a línguas são indeterminadas, há um espaço enunciativo de reflexividade e subjetividade que se constitui nas situações interativas de diversas práticas humanas, mas também no trabalho - tanto expressivo quanto interpretativo - levado a cabo pelos sujeitos com e sobre a linguagem; iii) os sentidos parecem ser garantidos a um só tempo "na língua e na sociedade" (Gadet, 1990); iv) os dados extraídos do contexto patológico são capazes de questionar e propor alternativas ao referencialismo.

Para dar materialidade a essas posições, procurarei então refletir sobre as seguintes questões: seria a linguagem de afásicos mais indeterminada que a de sujeitos não-afásicos (afinal, existiriam vários fatores que colaborariam para a indeterminação da linguagem do afásico: o déficit na organização sintática e a dificuldade de acesso ou de processamento lexical, as alterações fonéticas que afetam a compreensão da fala, a profusão de parafasias de diversas naturezas, as alterações semânticas que afetam distintos processos de significação, como a polissemia ou implícito)? Ou será que a linguagem de afásicos não seria em si mais indeterminada que a linguagem de sujeitos não-afásicos - ainda que se deva considerar o grau de comprometimento de processos lingüístico-cognitivos nas afasias? A linguagem do afásico estaria situada num grau máximo de indeterminação somente em função de um déficit lingüístico (ou metalingüístico, para sermos mais precisos)? Em sua tese de doutoramento, NovaesPinto (1999) pondera acertadamente que nesse caso estaríamos acreditando numa possibilidade de indeterminação quase absoluta, o que significaria, segundo Geraldi (1991), "trocar uma ilusão por outra", ou seja, por uma determinação absoluta. A propósito dessa questão, afirma Geraldi muito apropriadamente: "Acreditar numa indeterminação absoluta seria trocar uma ilusão por outra: a ilusão da uniformidade pela ilusão da multiplicidade indeterminada. Numa posição estaríamos negando o presente; na outra estaríamos negando o passado. Uma e outra negam os fatos. Uma e outra são negadas pelos fatos. Construir sentidos no processo interlocutivo demanda o uso de recursos expressivos: estes têm situacionalmente a garantia de sua semanticidade; e têm esta garantia precisamente por serem recursos expressivos que levam inevitavelmente o outro a um processo de compreensão, e este processo depende também das expressões usadas e não só supostas intenções que o interlocutor atribua ao locutor" (op.cit). 
Uma maneira interessante de discutirmos tais questões é verificar a forma pela qual afásicos reagem a diferentes fatores constitutivos da determinação referencial em contextos enunciativos. Assim, dentro do escopo deste artigo, veremos algumas situações que destacam o trabalho do afásico e seus interlocutores na manipulação dos embreantes como $e u, t u$ e ele, bem como na interpretação de enunciados proverbiais, em operações epilingüísticas e em comentários meta-enunciativos.

Com relação ao que ocorre com a linguagem de afásicos ou de sujeitos cuja linguagem tenha sido afetada por algum dano córtico-cognitivo, as discussões em torno do páthos da linguagem estão sempre marcadas - ao longo de nossa trajetória científicofilosófica - por um discurso logocêntrico, cujo compromisso com a questão da referência tem sido reduzida ao referencialismo, ao conhecimento metalingüístico do mundo, à busca da presença da lógica na linguagem (em detrimento de uma lógica própria $d a$ linguagem). Para muitos, essa seria a grande perda sofrida pelo sujeito afásico: a capacidade de, através da linguagem, localizar (e localizar adequadamente!) os objetos do mundo, ou os "objetos de discurso" (Cf. Mondada \& Dubois, 1995) - se quisermos fugir às clássicas dicotomias, como língua/exterioridade ou linguagem/mundo. Como ponderei em artigo anterior (2000), a linguagem cuja perda é lastimada é, na verdade, uma fantasmagoria, fruto de uma percepção idealizada que os homens têm feito de si mesmos, de seus cérebros e de seus comportamentos.

$\mathrm{O}$ enquadre diagnóstico dos desvios e inadequações lingüístico-cognitivas, por sua vez, tem-se dado basicamente a partir de uma mentalidade forjada desde a Gramática de Port-Royal até meados do século XX (quando novas abordagens sobre a questão do sentido e sobre o "bem dizer" foram introduzidas na Lingüística). Nessa mentalidade, vale sublinhar, a determinação da linguagem é a marca da expressão da vontade e da liberdade do "sujeito psicológico", implicando tal noção que ele é considerado a "fonte última de todo fato, discursivo ou outro" (Cf. Haroche, 1992:78).

\section{DA REFERENCIAÇÃO E DO REFERENCIALISMO: BREVES NOTAS}

Ainda que nos últimos anos, muitos autores tenham destacado em suas análises o caráter interativo da referenciação (como Koch, 1999; Marcuschi, 1994; ou Mondada \& Dubois, 1995, por exemplo), no campo dos estudos neuropsicológicos e neurolingüísticos é forte ainda o entendimento de que nas patologias neuropsicológicas (cerebrais, cognitivas) se encontram afetados - senão a língua enquanto sistema abstrato - os processos lógico-perceptivos (isto é, não lingüísticos) responsáveis pela identificação e controle da referência. Nessa perspectiva, o que estaria perdido ou alterado nas patologias linguístico-cognitivas seria o caráter metalingüístico e referencial da linguagem, a capacidade que a linguagem teria de representar ou autorizar as representações lógico-perceptivas do mundo ${ }^{3}$. De uma só vez, reduz-se aí a

\footnotetext{
${ }^{3}$ Tornou-se clássico afirmar sobre as afasias que elas perturbam a metalinguagem. Isso porque falar uma língua (e fazê-lo adequadamente) estaria subordinado à capacidade (lógico-perceptiva, bem entendido) de falar sobre esta língua. Porém, ao abrir o diálogo entre duas ordens, a da língua e a da exterioridade, o estudo enunciativo da metalinguagem introduz na Neurolingüística a "despsicologização" das explicações
} 
metalinguagem às operações metalingüísticas, e o componente "meta" a uma ordem da qual se exclui a linguagem e processos afeitos a ela.

De acordo com Vion (1992), a referenciação consiste na seleção, dentre a totalidade de eventos, de certos objetos do discurso. Porém, essa afirmação ainda trabalha com uma fronteira fortemente delimitada entre referência e referenciação, algo complicado quando se trabalha com linguagem ordinária, com objetos pragmáticodiscursivos.

Segundo Ducrot (1987), a "referenciação é parte integrante da enunciação". Neste artigo procuramos ampliar essa consideração de Ducrot, considerando que a referenciação é ela mesma um ato de enunciação.

O mundo que o sujeito constrói em seu relato depende em grande medida de suas escolhas lexicais, de suas intenções discursivas, do reconhecimento de implícitos culturais, do reconhecimento de elementos temáticos, das posturas meta-enunciativas dos interlocutores ${ }^{4}$, do tipo de relação que estabelece com os outros, de coordenadas dêiticas de que lança mão para transformar "referentes" em "objetos do discurso" ( $C f$. Mondada \& Dubois, 1995). Essa perspectiva prevê uma possibilidade de subjetividade em meio às múltiplas atividades psico-sociais realizadas pelos sujeitos.

Enquanto atividade discursiva, a referenciação tem a ver com uma "postura metaenunciativa" ( $C f$. Morato, 1999) dos sujeitos em relação aos objetos do discurso. Em outras palavras, a referenciação pode ser entendida como um fenômeno discursivo por explicitar enunciativamente os processos de significação nela envolvidos (o plano enunciativo da metalinguagem), por ser constituída por instâncias pragmáticas e culturais que presidem a utilização da linguagem, por ser marcada pelos aspectos sociais e intersubjetivos das interações que lhe são próprias. Assim, repostos na língua aqueles objetos tidos como heteróclitos por Saussure, a questão da referência prevê uma arbitragem de fatores que pressupõem, mas transcendem o lingüístico. Portanto, o que pode estar instável nas patologias de linguagem é precisamente a consideração do conjunto ou a seletividade desses fatores (lingüísticos, cognitivos, pragmáticos,

sobre a metalinguagem. É sabido que, tradicionalmente, se têm considerado os procedimentos "meta" como uma questão essencialmente cognitiva (a criança "ganha" ou "entra" na linguagem pela tomada de consciência do objeto lingüístico, pela atitude mental frente à linguagem e seu funcionamento; as afasias suprimiriam, por assim dizer, justamente essa capacidade lingüística de que os falantes são dotados, ou seja, "perder-se-ia" nas afasias não apenas a capacidade de falar sobre a linguagem, mas essa possibilidade de reflexividade da linguagem que consiste numa reação de reparação e de reconstituição de processos lingüísticos).

${ }^{4} \mathrm{O}$ estudo da postura meta-enunciativa (isto é, o movimento de distanciamento e reflexão dos sujeitos com relação ao dizer próprio e alheio), ao salientar a maneira como ele se "move na linguagem" (para usar uma expressão de Sírio Possenti), tende a confirmar a hipótese de que os modos de funcionamento do componente "meta" (relativos às atividades inferenciais verbais e não-verbais, à presença de semioses coocorrentes nas práticas discursivas, a diferentes processos de memória, a diferentes aspectos psicopragmáticos - como o processamento semântico-lexical, por exemplo) não são subsumidos pela língua $o u$ pela cognição; antes, eles são de responsabilidade de uma competência que articula enunciativamente um saber da língua e um saber do mundo. Trata-se de duas formas de conhecimento não sobredeterminadas e não alinhadas por um princípio de redundância ( $C f$. Benveniste, 1966/1989), mas ligadas ontogenticamente por uma relação de solidariedade que, longe de desaparecer nas afasias, atua de forma a eleger em muitos casos alternativas de significação. 
discursivos, afetivos, ideológicos) implicados na referenciação, sobre os quais os sujeitos se apóiam e trabalham para dar representabilidade às coisas do mundo.

Por afetarem a polissemia existente entre a língua (isto é, o sistema linguiístico) e a exterioridade pragmático-discursiva, duas zonas de conhecimento que se constituem mutuamente, as patologias tradicionalmente têm sido consideradas por distintas perspectivas teóricas um lugar interessante para o estudo das atividades inferenciais e referenciais dos falantes.

Em relação à questão da referência, especificamente, apenas alguns autores têm se dedicado a esse tema no campo das patologias. Alguns o fazem, naturalmente, estudando outras categorias teóricas, implicadas ou correlacionadas à questão da referência, como a metalinguagem, a inferência ou a significação lingüística. Todorov (1980), por exemplo, enfrentou o problema da referência no discurso de psicóticos, que "falam sem dizer", segundo ele ${ }^{5}$. Em minha tese de doutoramento (1995), enfrentei o problema da confabulação (tida no campo da pesquisa neuropsicológica como uma "mentira honesta", $C f$. Moscovith, 1989; ou como "produção de falsa informação sem intenção de iludir", $C f$. Berlyne, 1972), fenômeno em geral reservado equivocadamente aos contextos patológicos, e no qual tanto a linguagem, quanto a memória, parecem, à primeira vista, estar à deriva.

Quais seriam os elementos significativos para a construção da referência que estariam ausentes do discurso de sujeitos que confabulam, por exemplo?

Parece-nos que não são exatamente os elementos lingüísticos, como os que remetem os enunciados uns aos outros (elementos de coesão e de coerência). Pelo contrário, muitos dos textos produzidos por sujeitos potencialmente confabuladores são bastante coerentes e nem sempre apresentam problemas de coesão ao nível dos enunciados. Os problemas também não são aqueles relativos às proposições incompletas, aos empregos de verbos transitivos sem complemento, à ausência de conjunções semânticas. O bom uso (ou o uso indevido) de elementos dêiticos, por sua vez, não parece suficiente nem para fixar a referência nem para caracterizar a confabulação, ainda que isso seja importante e necessário para o engajamento nas situações interlocutivas ou propostas discursivas.

Se existe nas confabulações um problema de referência, como ele se apresenta, afinal? Ao que parece, manipular com relevância vários e diferentes processos referenciais que estão em jogo na significação.

O efeito mórbido da confabulação, ao contrário do discurso psicótico (que tem a ver com a atitude do sujeito que, ao proferi-lo, considera-o verdadeiro, $C f$. Foucault, 1963), parece ter como objeto o próprio discurso, e nisso ela se assemelha tanto à veridicção quanto à mentira, recebendo, pois, uma aplicação judiciosa da noção de verdade (e de realidade). O discurso cotidiano está repleto de exemplos de confabulação, espraiados em nossa vida prática, em nossa cultura. Alguns pertencem ao

\footnotetext{
${ }^{5}$ Para o autor, o fracasso da referência no discurso psicótico assume três formas, relativas à catatonia, à paranóia e à esquizofrenia: refúgio no silêncio (ou recusa da fala), criação de uma referência própria e subjetiva, que acaba por não fazer distinção entre real e imaginário (evocação de mundos fantásticos), falta ou impossibilidade de construção de referência via linguagem (alteração da metalinguagem, basicamente). $\mathrm{O}$ problema reside, assim, "naquilo de que se fala": quando fala o psicótico, não se sabe o que ele diz.
} 
anedotário, como uma pesquisa informal sobre o conhecimento enciclopédico feito há alguns anos por um jornal paulista. O repórter perguntava aos transeuntes, entre outras coisas, se eles tinham ouvido falar do concerto que Beethoven daria no Teatro Municipal de São Paulo. Como resposta, obtinha afirmações e comentários sobre a importância do evento para o Brasil etc.

Os dados de linguagem patológica são de fato interessantes para quem tem uma inclinação anti-referencialista com relação à linguagem. A visão anti-referencialista questiona uma concepção referencial de linguagem (pelo menos no que ela tem de formal, de causal), pois admite que seu objeto de análise deixa de ser o próprio mundo; seu objeto diz respeito ao mundo narrado, ao mundo enunciado, ao mundo enunciável: seu objeto de análise são os objetos de discurso. No anti-referencialismo não há possibilidade de homologia nem dicotomia entre a linguagem e as coisas, entre linguagem e cultura, entre objetos do mundo e objetos do discurso.

Mas a visão anti-referencialista questiona também o caráter representacional da linguagem. Ou seja, desde que o conhecimento da linguagem (suas regras próprias de constituição e de expressão) não se identifica com (isto é, não equivale ao) conhecimento que temos do mundo, o outro (nosso interlocutor, nossa audiência, nosso outro-eu, enfim, um outro empírico, não uma construção metateórica) nos é necessário para entendermos o que estamos a expressar ou a interpretar. Eis aqui um outro elemento que nos leva para uma visão não-referencial da linguagem: mesmo que consideremos que a linguagem tenha alguma capacidade de refletir algo, não parece ser a capacidade de refletir a si mesma, ou ao mundo, propriamente. E sim as condições (pragmáticas, interativas, discursivas) em que os sentidos são produzidos, estabilizados, determinados.

Finalmente, a visão anti-referencialista questiona a noção de metalinguagem reduzida a parâmetros logicistas, redirecionando a discussão para uma perspectiva enunciativa dos procedimentos meta ${ }^{6}$.

\section{SUBJETIVIDADE E REFERENCIAÇÃO: BREVES NOTAS}

Como enfrentar o problema da referenciação tendo em vista o caráter heterogêneo básico da linguagem? Como enfrentar esse problema no campo da linguagem afásica? Em que termos levantar essas questões no estudo da postura dos sujeitos em relação ao objeto do seu dizer (o dictum) e ao modo pelo qual eles se relacionam com o outro do seu discurso (o modus)?

\footnotetext{
${ }^{6} \mathrm{Se}$ nos afastarmos dos princípios logicistas da metalinguagem e, portanto, do compromisso formal (no sentido de causal) que submete a linguagem a uma ordem que não ela mesma (do cognitivo ou do mental, ou mesmo do cerebral), podemos postular uma natureza enunciativa para a metalinguagem. É isso o que alguns autores, certamente em decorrência dos estudos interacionistas dos anos 80 (sobretudo no campo da Psicolingüística e da Aquisição de Linguagem), vêm procurando fazer nos últimos anos: refiro-me a analistas do discurso que se pautam pelas análises inter e intra-discursivas da significação, aos psicolingüistas que se interessam pelos erros reorganizacionais, aos neurolingüistas (entre os quais me incluo) que procuram estabelecer uma perspectiva enunciativa-discursiva das relações entre linguagem e cognição.
} 
Em que bases podemos afirmar, parafraseando Bosi em seu livro "Memória e Sociedade - lembrança de velhos", que os afásicos também "trabalham" com e sobre a linguagem? Franchi, cuja posição sobre o caráter constitutivo da linguagem em relação ao (conhecimento, interpretação do) mundo é consoante à de autores como Humboldt, Benveniste e Granger, formula uma já conhecida passagem sobre isso: "Não há nada imanente na linguagem, salvo sua força criadora e constitutiva, embora certos 'cortes' metodológicos e restrições possam mostrar um quadro estável e constituído. Não há nada universal salvo o processo - a forma, a estrutura dessa atividade. A linguagem, pois, não é um dado ou um resultado; mas um trabalho que 'dá forma' ao conteúdo variável de nossas experiências, trabalho de construção, de retificação do 'vivido' que, ao mesmo tempo, constitui o simbólico mediante o qual se opera com a realidade e constitui a realidade como um sistema de referências em que aquele se torna significativo. Um trabalho coletivo, em que cada um se identifica com os outros e a eles se contrapõe, seja assumindo a história e a presença, seja exercendo suas opções solitárias".

Ao incluir a subjetividade no estudo da linguagem (e das relações entre linguagem e cognição), a perspectiva enunciativa torna mais explícita a transformação da língua em discurso, com base num caráter que é inexistente, por exemplo, no estruturalismo saussureano (que excluía o sujeito entre os demais objetos considerados heteróclitos). Fruto desse movimento, o empreendimento enunciativo de Benveniste e de autores cuja posição teórica poderíamos chamar enunciativo-discursiva (que se baseia em análises intra e interdiscursivas), se não rompe com a dicotomia língua-fala, faz irromper do contexto enunciativo a tese da indeterminação da linguagem.

\section{APRESENTAÇÃO E DISCUSSÃO DE DADOS NEUROLINGÜÍSTICOS}

\section{a) Subjetividade e manipulação lingüística da auto-referência}

Vejamos, a título de ilustração, alguns dados de um sujeito afásico em que fatores enunciativos estão de alguma forma concernidos à recomposição lingüística da autoreferência e à subjetividade. Vejamos como a intersubjetividade e o funcionamento enunciativo dos embreantes, por sua vez, se relacionam com a determinação referencial.

Nos dados (1) a (6) elencados a seguir (extraídos de um texto anterior de Coudry \& Morato, de 1988) podemos observar - num seguimento longitudinal de vários meses - o movimento enunciativo que permite a estabilização da manipulação lingüística da auto-referência, no caso de uma senhora afásica de 71 anos, $\mathrm{AD}$, que, após superar o estágio inicial de sua afasia, passa a se referir a si mesma na terceira pessoa.

Embora estejamos considerando aqui aspectos ligados a uma determinada instância enunciativa - a interlocução -, e embora o objetivo deste artigo seja precisamente destacar os movimentos enunciativos relativos à auto-referência, é preciso 
lembrar que outros fatores concorrem (ou co-ocorrem) na explicação do fenômeno em questão ${ }^{7}$.

$\mathrm{O}$ fato de os embreantes $\mathrm{eu}$, tu e ele serem vistos tradicionalmente enquanto sistema pronominal não impede ou rejeita o complicado debate sobre a noção de pessoa, que deriva de outra noção complexa, a da consciência de si, que também não pode - por sua vez - ser ligada de maneira direta (ou ser confundida) com a questão clássica da subjetividade ( $C f$. Jacques, 1982: 25).

Alguns lingüistas tentam mesmo definir claramente o que seria pessoa e o que seria pro-nome (Cf. Maingueneau, 1986/1996:11), como Benveniste e Jakobson. Para este último, por exemplo, o pronome ele seria categorialmente diferente das duas pessoas $e u$ e $t u$, pois seu valor referencial (instável, por excelência) dependeria sobremaneira do contexto lingüístico", ou seja, não estaria explicitado na situação interlocutiva.. O fato é que a definição do estatuto dos embreantes nas situações de enunciação nos remete à questão da reflexividade enunciativa, uma vez que eles podem, a cada enunciação, mudar de sentido (embora guardem uma "significação geral própria", diferente da dos nomes ordinários, que teriam uma maior estabilidade referencial, $C f$. Jakobson, 1963:179).

Assim, não se pode deixar de considerar que o sujeito que assume uma determinada posição como locutor na enunciação (eu, tu, ele) assume também um lugar institucional (comunicativo, identitário, discursivo). Se levarmos em conta a tese da ilusão da subjetividade (ou de identificação pessoal) e a discussão que se projeta em torno da relação da terceira pessoa com as outras duas (eu, tu), a questão se torna ainda mais complicada: o que haveria de subjetivo na instância produtora de sua linguagem no caso da senhora $\mathrm{AD}$, que preserva os pronomes possessivos e se refere a si mesma em terceira pessoa em situações interlocutivas, que são intersubjetivas por excelência? Quanto a este aspecto, vale a pena observar a seguinte passagem de Maingueneau: " $O s$ pronomes possessivos substantivos, por sua vez, associam uma retomada pronominal a uma relação do tipo meu/teu/nosso/vosso + nome: o teu é tanto 'o $N$ que é teu' quanto 'a ação que tu fazes'. Ainda que este conjunto de pronomes contenha embreantes de pessoa (o meu, por exemplo, contém um eu), eles dependem entretanto da não-pessoa: o meu designa um objeto do qual eu falo, da mesma maneira que 'a mesa' ou 'Paulo' “(1986/1996:12). (ênfase minha)

Ao que parece, as explicações benvenisteanas, bem como as de outros autores do quadro teórico enunciativo, retêm uma grande parcela de razão. Mas não se pode extrair do fato de dizer "eu" toda a verdade sobre o fenômeno da subjetividade (assim como falar consigo mesmo não implica refletir sobre si mesmo). Ou seja, o valor de posição pessoal não parece ser suficiente para dar referência à pessoa; tampouco a renúncia à centralidade do locutor deve inviabilizar ou simplificar a questão da subjetividade na linguagem (lembro aqui que, contrariamente à imposição das

\footnotetext{
${ }^{7}$ Poderiam ser aventadas, para essa instabilidade da auto-referência, comparações com explicações que remontam aos estudos aquisicionais, como a questão da complexidade da auto-representação (isto é, o reconhecimento de si mesmo como "objeto") ou uma espécie de gosto inicial da criança pela "despessoalização" (relativa ao fato de a criança "entrar" na linguagem assumindo o lugar da terceira pessoa, fato tratado, por exemplo, por L. Irigaray).
} 
categorias eu e tu como definidoras da relação intersubjetiva, há autores que consideram que mantemos uma relação de dependência mútua entre as três instâncias eu, tu, ele -, desde que a (inter)subjetividade na enunciação é sempre estabelecida "simbolicamente") ${ }^{8}$.

O valor relacional empregado tanto por eu quanto por ela para dar referência a si mesma - algo marcado de maneira peculiar na linguagem de AD - ressalta o caráter intersubjetivo da enunciação. Ao que parece, é mais esse caráter que está em jogo na ausência e posteriormente na instabilidade da adequação do pronome "pessoal" na linguagem de $\mathrm{AD}$ que propriamente o sujeito do dizer.

Com relação ao que acontece no campo das patologias em termos de autoreferência poderíamos ainda evocar as reflexões de Foucault (em "O nascimento da clínica", por exemplo), nas quais o autor aponta a existência de uma duplicidade do sujeito (provocada por uma espécie de estranhamento em relação a si mesmo; a clivagem partiria da existência de um "sujeito que se estranha"): na linguagem de AD, o embreante ela ocupa ora o lugar de uma identidade virtual ("ela e o meu marido dela"), ora concerne ao que é recusado ou rejeitado ("eu faço um negócio e ela não consegue"). Há ainda a possibilidade de AD estar querendo dizer algo como: "esse 'ela' a que me refiro pode ser interpelado tanto por você quanto por mim", o que implica a existência de relações diádicas entre as três instâncias (e não apenas entre "eu" e "tu") que os sujeitos podem assumir enquanto enunciadores (ora o lugar do $e u$, ora o lugar do $t u$, ora o lugar do ele).

Além disso, tendo em vista que nas situações interlocutivas como as que se seguem abaixo encontramos comentários, explicações, narrativas e descrições - os dados (1) e (2) foram extraídos de um episódio em que AD mostra à Iem seu álbum de família - , há de se considerar também uma espécie de "subjetividade subjetivada" que advém tanto do distanciamento provocado tanto pelo deslocamento espácio-temporal quanto pela apreciação de fotografias antigas (quando o sujeito, hoje afásico e debilitado, se encontrava saudável e eficaz no uso da linguagem).

Com o intuito de ajudar $\mathrm{AD}$ a assumir diferentes posições enunciativas e, dessa maneira, recompor lingüisticamente aspectos ligados ao trabalho referencial e à subjetividade, foi introduzida na interação entre $\mathrm{AD}$ e a investigadora (situação diádica clássica em que $\mathrm{AD}$ era interpelada como $t u$ e instada a falar do lugar da primeira pessoa) outra pessoa afásica, que passou - pouco a pouco - a ocupar o lugar "do terceiro" nos enunciados de AD. A manipulação lingüística da auto-referência, no quadro de uma subjetividade marcada tanto por eu quanto por ela (e que surge lingüisticamente, vale lembrar, na posição da terceira pessoa), é assim recomposta em instância interlocutiva, em função do reconhecimento da presença do interlocutor e dos papéis enunciativos assumidos por todos na interlocução. De um lado, os dados de AD servem para contrariar as considerações negativas ou excludentes da terceira pessoa,

\footnotetext{
${ }^{8}$ É o que salienta Jacques: "Mais la tendance des linguistes est à souligner l'hétérogénéité des trois personnes. Selon notre perspective propre, la troisième personne est d'une certaine manière relative aux deux premières dans le circuit de leur entretien, par rapport auquel elle est précisément troisième. La valeur de 'il' est bien en rupture avec les valeurs de 'je' et de 'tu' des participants, mais c'est en restant dans une certaine relation avec eux" (1982:55).
} 
chamada por Benveniste de "não-pessoa"; de outro, sugerem que a relação entre os três embreantes ou as três pessoas (eu, tu, ele) é essencialmente dinâmica e constitutiva.

Embora se soubesse pelo relato de familiares que a instabilidade da manipulação da auto-referência fosse na linguagem da $\mathrm{AD}$ uma constante em determinado período do seu quadro afásico, cabe mencionar aqui que seria interessante analisar a maneira pela qual ela se dava em outros contextos enunciativos em que seus interlocutores não estivessem tão atentos ou interessados na dêixis ou na referenciação. De todo modo, esse episódio torna evidente que falar com alguém nem sempre é instituir uma relação intersubjetiva entre interlocutores (não é à toa que $\mathrm{AD}$ era incapaz de, sob comando de um familiar ou de um investigador-, dizer "eu" para se referir a si mesma).

(1)

$\mathrm{AD}$ - //mostrando à Iem as fotos do álbum de família, em que aparece junto ao marido e os netos// Ela com meu neto e minha neta //apontando para sua foto ao lado do marido// Ela e ele...

Iem - Aqui é a mulher dele?

$\mathrm{AD}$ - É, é ela.

$\mathrm{AD}$ - //no mesmo contexto do episódio anterior// Meus filhos pequenos, meu marido... Iem - Seu marido...

$\mathrm{AD}$ - //apontando para a sua foto ao lado do marido// Ela e o meu marido dela //AD ri, como que flagrando um ato falholl

$\mathrm{AD}$ - //irritada, comentando suas dificuldades lingüísticas e motoras// Eu faço um negócio e ela não consegue!

Iem - Quem não consegue?

$\mathrm{AD}$ - Eu! Eu não ando bem, eu noto, viu? O Plínio achou que ela...eu //procede a uma rápida reformulação// estava....estou bem melhor.

(4)

//Iem conta à $A D$ a viagem que fizera ao Mato Grosso//

Iem - Fui também para o Pantanal.

$\mathrm{AD}$ - Ah, foste? Porque lá é...

Iem - Lindo...

$\mathrm{AD}$ - E tu achaste lindo?

Iem - Sim, sim. Pena que haja tanta matança de jacaré. O Governo não está muito atento...

$\mathrm{AD}$ - E com o que ele está atento? //risos//

//AD relata à Iem um encontro que tivera com outra senhora afásicall

$\mathrm{AD}$ - Ela tá bem. 
Iem - Ela tá mais animada agora?

$\mathrm{AD}$ - Eu acho, ela ela está ela come //hesitações// melhor pra //hesitações//melhor pra comer não. Melhor do que eu //ri//

(6)

I/AD comenta com Iem as opiniões de amigos a respeito de suas dificuldades lingüísticas e motoras//

$\mathrm{AD}$ - Mas elas sabem que eu vou saber, ela sabe.

Iem - Ela quem? //AD ri, aparentemente da expressão de exagerada surpresa de Iem//

$\mathrm{AD}$ - As pessoas. "Ela" é as pessoas, as pessoas //ri novamente// Pensou que eu não sabia mais? Agora ela é eu.

\section{b) Subjetividade e atividade referencial no quadro das chamadas operações epilingüísticas.}

A partir do termo cunhado por Culioli (1968) tem-se que a existência de atividades epilingüísticas dá-se sob a forma de uma de uma espécie de reflexão do sujeito em relação à linguagem, o que o faz agir sobre ela de forma algo distanciada.

Os dados de afásicos que exibem atividades de reformulação do próprio dizer e da própria fala, de auto ou hetero-correção apresentam fortes indícios de que a linguagem não existe senão em função de um interlocutor, e em meio a propriedades e instâncias interativas. Fenômenos freqüentemente observados no Centro de Convivência de Afásicos $(\mathrm{CCA})^{9}$ indicam que a interlocução, dentre as práticas discursivas mais diversas, é fundamental para a recomposição da subjetividade e condição para a possibilidade de reflexividade da linguagem.

Observa-se de maneira bastante viva nas práticas discursivas do CCA o empenho de seus interlocutores para que o sujeito afásico possa assumir distintas posições enunciativas, o que inclui o reconhecimento de si mesmo como falante, como enunciador, como sujeito da e na linguagem. Nesse sentido, tanto um interlocutor qualquer (um outro afásico ou um dos pesquisadores que freqüentam o CCA) quanto a audiência (o "grupo") atuam como uma espécie de réplica da sociedade (Bakhtin, 1929/1995) e da memória coletiva, atuam como parceiros de um jogo comum - o jogo discursivo que nos obriga a constantes tarefas de reformulação, de ajustes enunciativos, de indicações e reconhecimentos de intenções manifestas ou pretendidas, de adequação do estilo e do "código" comum.

Ainda que muitos autores defendam a distinção entre o metalingüístico e o epilingüístico (como o próprio Culioli e boa parte dos psicolingüistas), podemos considerar a questão como estando ainda longe de ser (ou estar) resolvida. Por outro lado, ainda que não tão numerosos como os primeiros, há autores (entre os quais me incluo) que consideram que, na realidade, fora de uma perspectiva fortemente

\footnotetext{
${ }^{9}$ O Centro de Convivência de Afásicos (CCA), ligado ao Laboratório de Neurolingüística (LABONE), é um espaço de interação entre pessoas afásicas e não-afásicas. Fruto de um convênio com o Departamento de Neurologia da Faculdade de Ciências Médicas, tem sua sede no Instituto de Estudos da Linguagem (IEL) da Universidade Estadual de Campinas.
} 
cognitivista, uma divisão entre ambas é insustentável. Com isso, são levados a considerar apenas um termo, metalinguagem, para se referir à capacidade mais ou menos consciente que os falantes têm do uso que fazem da língua (e da linguagem).

Contudo, uma outra distinção deve ser examinada, ainda que brevemente. Trata-se da que opõe atividades epilingüísticas e meta-enunciativas. Para enfrentar essa questão, é fundamental que nos posicionemos, entre outras coisas, com relação ao seguinte problema: toda tomada de fala implica necessariamente um distanciamento do sujeito sobre o dizer, próprio ou alheio? Para Franchi (1977), Geraldi (1991) e Ducrot (1980), por exemplo, sim (este último chega a afirmar, em "Les mots du discours": "A partir do momento que falamos, falamos de nossa fala"); já para Mainguenau (1987/1989) e Authier-Révuz (1998), por exemplo, não. Authier-Révuz, associando a atividade metalingüística corrente com a epilingüística, assim especifica a reflexividade que constitui a modalidade autonímica: "auto-representação do dizer que se vai fazendo, por oposição ao que, no campo do epilingüístico, é discurso sobre a linguagem em geral, sobre um outro discurso, sobre o discurso do outro na interação, no diálogo (op.cit. p. 181).

Vejamos abaixo um exemplo do estabelecimento das relações entre as chamadas operações epilinguiísticas e o fenômeno meta-enunciativo. Ele foi extraído de um encontro do CCA de 17/06/98, durante a Copa do Mundo (futebol). MS, um senhor afásico, comenta com os demais participantes sobre a ausência de um jogador que ganhara notoriedade na Copa anterior, Roger Milla, da seleção nacional de Camarões. O comentário surge por ocasião do jogo Brasil x Camarões, da qual o atacante africano não participaria. Apesar da instabilidade sintático-semântica que caracteriza seu quadro afásico, MS procede abaixo a uma reformulação do seu dizer tendo por base justamente uma análise sintática e, por motivação, a reação de sua audiência:

MS - “O Camarões tá...ele...não...pega...//começa de novo, reestruturando seu enunciado//Um camarão...um dos Camarões...ele//todos no CCA riem e ele ri também//...Eles tava um um...Eu falo do meu modo...não dá pra mim, sabe como

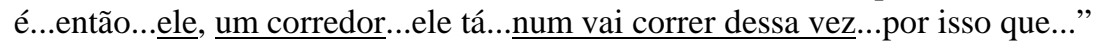

Contudo, nem toda reformulação do dizer implica um distanciamento metaenunciativo. Vejamos dois exemplos que expressam algo muito recorrente durante os encontros e atividades do CCA (os dados foram extraídos do primeiro relatório de uma pesquisa coletiva voltada para a análise de vários aspectos relacionados ao Centro que coordeno e que tem apoio da Fapesp ${ }^{10}$ ). No exemplo (8), o sujeito CI procede a reformulações tendo em vista a adequação da forma (ele ajusta construções parafásicas, como ameaçou/avisou, bem como reage metonimicamente a dificuldades de seleção lexical) e das intenções comunicativas (da qual depende a manutenção da proposta conversacional). No exemplo (9) a ocorrência de uma parafasia ("Heroína" por "Erundina") resulta, enunciativamente, um fenômeno semelhante a um ato falho; do mesmo modo, a instabilidade entre "prefeito" e "presidente" para designar o cargo

${ }^{10}$ (Proc. 99/07055-6). 
pleiteado pelo ex-presidente Fernando Collor por ocasião de novo momento eleitoral do País em 2000 (o de prefeito da cidade de São Paulo), indica bem como os sujeitos (afásicos ou não-afásicos) operam com relação ao processamento lexical (isto é, num ambiente lingüístico-pragmático no qual intervém a memória discursiva):

//CI chega atrasado à reunião e comenta sobre a greve dos ônibus e seus motivos. Justifica, ainda, sua ausência na sessão anterior//

CI - Eu não vim porque é...é: é:tava gripado.

JB - É...

Iat - Greve, gripe, tudo com $\mathrm{g}$.

CI - Então, aí a meteo....meteo....meteo....meteorologia ameaçou...é....avisou que ia chover à tarde, aí eu fiquei gripado, aí eu não posso carregar guarda-chuva, eu só tenho um.../lfez gesto cobrindo a cabeçal/ uma...

Imc - Capa!

CI - Capa, não! Ah...a: uma blusa com uma capa, é...

Imc - Capuz!

CI - Capuz!

//O grupo lê um artigo na revista "Veja" sobre a festa aniversário de 50 anos do expresidente Fernando Collor de Mello, que parece ser, pelo teor do texto, uma preparação para as eleições municipais de 2000. Em seguida, os participantes do CCA passam a comentar o texto lido por todos. No trecho abaixo, a pesquisadora (Iem) questiona CI//

Iem - O senhor acha que ele pode tentar sair o ano que vem, pra prefeito? Ele acha muito "lixo", eu tenho a impressão, candidatura pra prefeito.

CI - Ele vai ser pres...feito de São Paulo.

Iem - É, porque dá uma visibilidade, assim, né?

CI - É, porque, presi...prefeito de São Paulo, o que o cara tem que fazer é:...car cargo político.

Iem - Mas quais os candidatáveis, já?

CI - Coller, Collor, Maluf...

Iem - Marta...

CI - Marta Suplicy...

Iem - A Erun...

CI - A heroína...

Iem - Êpa!

CI - Erundina...//risos dos demais, que parecem ter notado o ato falho de CI, que se mantém sério//

Iem - //rindo, falando mais para o grupo do que para CI em particular// Que é uma forma de heroína... 


\section{c) Subjetividade e determinação referencial nos processos meta-enunciativos}

Segundo Authier-Révuz (1998:181-182), a meta-enunciação, enquanto configuração enunciativa, diz respeito a dois campos, o da metalinguagem e o da enunciação. Concerne, segundo a autora, à metalinguagem natural, interna à língua e observável (por oposição às metalinguagens lógicas, construídas, externas à língua); dá acesso às representações dos sujeitos a propósito da linguagem, do sentido, da comunicação. As formas meta-enunciativas - pelo exercício de sua sui-referencialidade - salientam esse exercício da metalinguagem e da reflexividade enunciativa.

$\mathrm{Na}$ pesquisa que venho empreendendo com apoio do $\mathrm{CNPq}^{11}$, parto do pressuposto de que o estudo de formas meta-enunciativas pode se mostrar produtivo para as questões que estreitam o lingüístico e o cognitivo no entendimento de várias ações humanas; do mesmo modo, ele abre interessantes possibilidades de análise para o antigo problema linguagem/cognição (existiriam procedimentos "meta" independentes da linguagem?) e ainda revigora, trazendo-as para um domínio enunciativo, a questão da referenciação e a da subjetividade nas afasias.

Em poucas palavras, o estudo de processos enunciativos que se organizam por uma relação complexa com o discurso do outro ou enunciados pré-construídos parece ser um lugar interessante para a investigação dos fatores de constituição do sentido e do funcionamento lingüístico-cognitivo em questão nas atitudes interpretativas e expressivas de sujeitos afetados pela lesão cerebral.

Estando a relação do sujeito afásico com a língua, seus interlocutores e consigo mesmo mais desestabilizada do que no contexto "normal", os expedientes discursivos de que lança mão acabam por permitir alguma distinção entre as situações que indiciam um trabalho que ele realiza sobre a linguagem daquelas em que os problemas lingüístico-cognitivos condicionam, de certa forma, esse trabalho.

Um dos princípios que regem essa pesquisa é que os procedimentos meta (não reduzidos a uma espécie de habilidade ou consciência metalingüística apriorística e alheia à linguagem e seu funcionamento) dizem respeito a uma competência pragmático-discursiva que relaciona o lingüístico e o cognitivo, isto é, não os toma como zonas do conhecimento heterogêneas entre si. Daí o fato de que a alteração de uma metalinguagem corrente ou natural (sobre a língua stricto sensu) não parece ser capaz de destruir a capacidade discursiva do sujeito. Entretanto, essa competência pragmática deve ser pensada enunciativamente, pois as atividades dos sujeitos não são concebidas como sendo de apropriação, porque "a partir deste conceito, fica excluído o fato de que o locutor age também sobre a língua, já que põe em evidência apenas a ação entre e sobre os interlocutores através da língua" (Possenti, 1988:49). No limite, as afasias, perturbando um e outro saber (da língua, do mundo), deixam "entrever", por assim dizer, uma relação que é, ontologicamente, de solidariedade.

Os procedimentos meta (relativos a processos de significação verbal e não-verbal) demandam diferentes níveis de reflexão dos sujeitos sobre a linguagem e essa reflexão, que também torna o sujeito um "observador das palavras" (na feliz expressão de

${ }^{11}$ Proc. 301396/96-5. 
Authier-Révuz), envolve um trabalho sobre a língua e a exterioridade. Além disso, como o conhecimento da linguagem, suas regras próprias e seus efeitos de sentido não equivale ao conhecimento que temos do mundo, o outro (nosso interlocutor, nossa audiência, nossa dialogia interna) nos é necessário para procedermos a gestos interpretativos. Eis aqui um outro elemento que nos leva para uma visão nãorepresentacional da linguagem: as não-coincidências enunciativas de que fala AuthierRévuz (1998).

Tendo em vista o movimento teórico esboçado acima, o fenômeno metaenunciativo surge como o lugar onde essa competência pragmático-enunciativa se faz mais "explícita", indicando o percurso polissêmico da relação entre a língua e o (inter)discurso, bem como o tipo de solidariedade que pode existir entre os processos lingüísticos e os cognitivos.

De maneira sutil, como na modalização autonímica, a polifonia que marca os enunciados proverbiais faz modular a responsabilidade pelo enunciado (Maingueneau, 2000:169), o que permite "ao enunciador apoiar sua fala sobre a fala de um outro". Essa modulação não ocorreria, sem dúvida, sem o concurso da competência pragmático-discursiva do enunciador e sem que ele atue meta-enunciativamente sobre sua fala e sobre o outro de seu discurso.

Aquele que profere um enunciado proverbial, ou aquele que interpreta um provérbio pode não explicitar a sua fonte (que em geral é apagada), mas deve reconhecer seus pré-construídos, apoiando-se em suas propriedades lingüísticas e numa memória cultural, discursiva (afinal, o provérbio é interpretado "fora de qualquer contexto particular", como lembra Maingueneau, 2000:171); deve, ainda, levar em conta que o provérbio é proferido com um ethos específico.

A fim de verificar como esse movimento enunciativo se processa em situações de instabilidade linguístico-cognitiva, seguem abaixo os gestos interpretativos de três sujeitos afásicos quando lhes foi apresentado um provérbio para que fosse interpretado ou para que fosse incluído em alguma situação cotidiana na qual caberia o seu uso (ver Morato, 2001). O provérbio é "Feliz foi Adão que não teve sogra". ${ }^{12}$ Vejamos o que dizem os sujeitos:

(10)

CI: É um provérbio conhecido, né? É muito usado, que é falar mal da sogra, então eu não falo mal da sogra, eu gosto da sogra, eu tive três sogras, né? Então dá pra perceber, eu tive sorte com as sogras, é grande amiga, uma morreu, outra tá viva, e a terceira mora perto de casa. Me dou bem com as sogras, esse ditado não é pra mim.

(11)

MS: Olha, "Feliz foi Adão que não teve sogra”, eu, eu, eu, eu da minha sogra eu falo, porque ela era uma mulher, é, é distinta que ela, ela foi uma heroína, eu falava da minha sogra, eu não posso falar da minha sogra, não é, é teve dez filhos e a mulher

\footnotetext{
${ }^{12}$ Este provérbio, bem como sua análise, consta do protocolo de investigação elaborado por Sandra Cazelato em seu projeto de Iniciação Científica (apoiado pela FAPESP) por mim orientado em 1999.
} 
que casou, casaram, né, e também não posso falar da minha sogra porque ela fez também uma, ela, ela fez a mulher que eu tenho, ela um, ela uma batalhadora, eu não posso falar da sogra.(...) É que o Adão não teve sogra porque ele, ele, ele, Deus não deu sogra pra ele, ele. Adão foi Deus que deu a mulher pra ele, mas porque ele não teve sogra, porque ele foi o homem que Deus mandou e a mulher que deu pra ele. Ele não teve sogra.

(12)

CL /lespantada, após ouvir o provérbio, indagando à investigadora// Ah é, ele não se casou?

VD: //rindo// Foi feliz, deixa eu ver uma situação que ele foi feliz. Isso...isso aí já é uma piada...Ele foi sempre só.

O provérbio em questão, para ser interpretado, exige conhecimento (enciclopédico) acerca de quem foi Adão e conhecimento sobre o universo discursivo no âmbito do qual circula o conceito de sogra em nossa sociedade. Portanto, é preciso conhecimento de mundo para manipular e interpretar os recursos expressivos que resultam nos efeitos da língua e do discurso. Na tarefa interpretativa, o sujeito, como um co-enunciador, tratará de fazer a relação entre a situação particular que o evoca e os pré-construídos estabelecidos no enunciado proverbial.

Dentre os processos lingüístico-discursivos implicados no trabalho metaenunciativo com relação aos provérbios destacam-se as inferências semânticopragmáticas realizadas pelos sujeitos (reconhecimento de objetos investidos de propriedades semânticas, pressupostos e/ou implícitos culturais), a passagem do plano enunciativo do uso para o plano enunciativo da menção, o reconhecimento dos efeitos dos sentidos em uma determinada enunciação proverbial, as diferentes posições e fontes enunciativas, a inscrição lingüística em pré-construídos (isto é, remissão à memória discursiva).

No caso desse provérbio, em particular, os sujeitos trabalharam semânticopragmaticamente sobre ele: derivaram desse enunciado propriedades e relações semânticas (sogra/genro; mãe/filha; marido/mulher), evocaram um conhecimento enciclopédico (Adão foi o primeiro homem, criado por Deus; logo, não tinha sogra) e um pré-construído cultural (é sorte ter boas sogras, que normalmente são vistas como perfeitas megeras).

Embora façam uma leitura acentuadamente pessoal do provérbio, e embora esbarrem em dificuldades de ordem metalingüística, os sujeitos não chegam a retirar dele a situação enunciativa a que historicamente pertence (com exceção de CL, no dado (12), que identifica Adão com algum sujeito empírico). Com isso, observa-se que não basta o conhecimento semântico-lingüístico para atuar com a produção e a interpretação de sentidos. É a partir da situação enunciativa e de seus constituintes que aquilo que o sujeito identificou na língua passou a "fazer" sentido para ele (VD, no dado 13, considera o provérbio, ou o sentido nele veiculado, uma "piada"). 
O que é importante destacar nesta seção é que, ainda que afetados pela afasia, esses sujeitos reconheceram os implícitos culturais envolvidos no provérbio, realizaram inferências relevantes e assumiram diferentes posições na enunciação; tudo isso é fundamental para caracterizar o trabalho lingüístico-discursivo, e também cognitivo, requerido pelas formas meta-enunciativas.

\section{À GUISA DE CONCLUSÃO...}

A crucial importância da observação dos fenômenos pragmáticos e enunciativos no contexto patológico para a reflexão lingüística reside no fato de que os dados da patologia confrontam (e não contrariam) o que acontece no discurso normal (se entendermos que há continuidade e não ruptura entre normalidade e patologia). O que ocorre no contexto patológico não nos leva simplesmente a refletir dentro de um esquema argumentativo negativo a respeito dos fenômenos lingǘ́stico-discursivos normais. Na verdade, os fatos patológicos, em função da falta, do excesso ou da disfunção de certos aspectos, nos ajudam a pensar em processos que se encontram em geral "amalgamados" no discurso cotidiano. Em suma, eles nos fazem pensar em aspectos que estão presentes na constituição de todo discurso, mesmo que não falemos deles por um compromisso com uma concepção idealizada de normalidade, de linguagem, de cognição.

Com base no exposto, podemos levantar algumas reflexões em torno do tema deste artigo:

a) a linguagem de sujeitos afásicos não parece ser em si mais indeterminada que a linguagem de sujeitos não-afásicos; contudo, a determinação da linguagem (e do sentido) no contexto patológico parece depender mais fortemente da presença e do papel de seus interlocutores;

b) os sujeitos afásicos, ainda que sob o impacto da alteração de aspectos lingüísticos e cognitivos, trabalham sobre e com a linguagem; dessa maneira, eles atuam com processos alternativos disponíveis, selecionados por eles ou pelos seus interlocutores numa situação enunciativa dada e tendo em vista os efeitos de sentido pretendidos;

c) a determinação (como a indeterminação) se decide na relação com o outro e em relação ao outro; as competências pragmáticas dos interlocutores concernem tanto à construção do sentido quanto à sua explicitação;

d) a análise enunciativa do trabalho realizado pelos sujeitos afásicos sobre a linguagem pode indicar que sua competência pragmática não está destruída porque a língua foi destruída ou porque os sujeitos cérebro-lesados se encontram mais instáveis cognitivamente; dizer que as afasias afetam o lingüístico ou o cognitivo enquanto duas dimensões distintas impede que entendamos o que permanece, o que se mantém, o que se restabelece após o dano cerebral;

e) o estudo dos processos de referenciação nas afasias, sublinhando o movimento do sujeito em relação ao seu dizer e ao dizer do outro, tende a apoiar a hipótese 
segundo a qual os meios de determinação da linguagem passam pelos processos de explicitação da significação e pelas diferentes posições que os sujeitos ocupam na relação estabelecida enunciativamente entre língua e exterioridade;

f) um dos grandes desafios da Neurolingüística parece ser decididamente não o estabelecimento de uma relação factual entre distúrbios lingüísticos e cognitivos, mas a relação epistemológica entre essas duas formas do conhecimento humano, linguagem e cognição. As práticas discursivas e as situações de enunciação são um lugar privilegiado para esse tipo de estudo, uma vez que "refutam precisamente o corte que se opera entre o lingüístico e o “extralingüístico"” (Maingueneau, 1986/1996:6).

\section{$\overline{\text { REFERENCIAS }}$}

AUTHIER-REVUZ, J. (1998). Palavras incertas - As não-coincidências do dizer. Campinas: Ed. da Unicamp.

BAKHTIN, M. (1995). Marxismo e Filosofia da Linguagem. São Paulo: Hucitec. (1997). Estética da criação verbal. São Paulo: Martins Fontes.

BENVENISTE, É. (1989). Problemas de Lingüística Geral I. Campinas: Pontes.

BERLYNE, N. (1972). Confabulation. British Journal of Psychiatry 120: 31-39.

COUDRY, M.I.H. \& MORATO, E.M. (1988). A ação reguladora da interlocução e de operações epilingüísticas sobre objetos lingüísticos. Cadernos de Estudos Lingüísticos 15: 117-136.

CAZELATO, S. O estudo de formas meta-enunciativas em sujeitos afásicos: A enunciação proverbial. Projeto de Iniciação Científica/FAPESP (Orientadora: Edwiges Maria Morato).

CULIOLI, A. La formalisation en Linguistique. Cahiers pour l'analyse 9:106-117.

DUCROT, O. (1980). Les mots du discous. Paris: Minuit. . (1987). O dizer e o dito. Campinas: Pontes.

FOUCAULT, M. (1963). Naissance de la clinique. Une archéologie du regard medical. Paris: PUF. (1969). L'Archéologie du savoir. Paris: Gallimard.

FRANCHI, C. Linguagem - atividade constitutiva. Almanaque 5: 9-27.

GADET, F. (1990). Prefácio. Por uma análise automática do discurso (F. Gadet \& T. Hank, orgs). Campinas: Editora da Unicamp.

GERALDI, J.W. (1991). Portos de Passagem. São Paulo: Martins Fontes.

HAROCHE, C. (1992). Da anulação à emergência do sujeito: os paradoxos da literalidade no discurso (elementos para uma história do individualismo). Cadernos PUC 8:61-86.

JACQUES, F. (1982). Différence et Subjectivité. Paris: Aubier Montaigne.

JAKOBSON, R. (1963). Les embrayeurs, les categories verbales et le verbe russe. Essais de linguistique générale. Paris: Minuit.

KOCH, I.G.V. (1999). Referenciação: construção discursiva. (mimeo). 
MAINGUENEAU, D. (1996). Elementos de lingüística para o texto literário. São Paulo: Martins Fontes. . (1989). Novas tendências em Análise do Discurso. Campinas: Pontes. . (2000). Análise de textos de comunicação. São Paulo: Cortez.

MARCUSCHI, L.A. (1994). Estratégias de identificação referencial na interação face a face (mimeo).

MONDADA, L. \& DUBOIS, D. (1995). Construction des objets de discours et catégorisation: une approche des processus de référentiation. In.: Du syntagme nominal aux objets de discours: SN complexes, nominalisations, anaphors. (orgs. A Berrendonner \& M-J Reichler-Béguelin), TRANEL 23:273-302.

MORATO, E.M. (1995). O discurso à deriva ou as sem-razões do sentido: um estudo da confabulação no contexto neuropsicológico. Tese de Doutoramento. IEL/Unicamp. Inédito. (1999). Afasia e heterogeneidade discursiva. Investigando a linguagem. (orgs. Loni Grimm Cabral \& José Morais). Florianópolis: Editora Mulheres.

. (2000). As afasias entre o normal e o patológico. Direito à Fala - a questão do conceito lingüístico (orgs. Fábio Lopes \& Heronides Moura). Florianópolis: Insular.

. (2001). A construção meta-enunciativa na linguagem de sujeitos afásicos: subsídios para um protocolo de investigação neurolingüística (Proc./CNPq 301396/96-5), Relatório de Pesquisa.

NOVAES-PINTO, R.C. (1999). "A contribuição do estudo discursivo para uma análise crítica das categorias clínicas” Tese de Doutoramento. IEL/Unicamp. Inédito.

POSSENTI, S. (1988). Discurso, estilo e subjetividade. São Paulo, Martins Fontes.

THÉVOZ, M. (1978). Le langage la rupture. Paris: PUF.

TODOROV, T. (1980). Les genres du discours. Paris: Minuit.

VION, R. (1992). La communication verbale - Analyse des interactions. Paris: Hachette.

WITTGENSTEIN, L. (1975). Investigações Filosóficas. São Paulo: Abril. 